Correspondents are asked to be brief.

Specialty of Haematology

T. Crawford, P.R.C.PATH. ............ 106

Barbiturate-induced Injection Lesions

F. E. Camps, F.R.C.P., and Ann E. Robinson, PH.D......................106

Insulin Mixtures and Hypoglycaemia

D. N. S. Malone, M.R.C.P.ED. . . . . . . . 106

Morphine a Spasmolytic? J. A. Ross, F.R.C.S.ED., and J. M. T.

Typing the Gonococcus

R. Irene Hutchinson, M.D. . . . . . . . . . . . 107

Migrating Intravenous Catheter

K. M. Moghissi, F.R.C.s., and H. H. Bentall F.R.C.s.....................107

Haemophilus aphrophilus Endocarditis

Major A. J. Spicer, M.R.C.P........... 108
Cervico-oculo-acoustic Dysplasia

D. A. A. Primrose, M.D. . . . . . . . . 108

Illustrated Lectures

C. F. Hawkins, F.R.C.P. . . . . . . . . . 108

Acute Malaria in Newborn Infants

N. E. Okeke, M.D. . . . . . . . . . . . 108

Tetanus

M. Ellis, F.R.C.s. . . . . . . . . . . . . . 109

Emotional Factors and Colitis

J. D. Gomersall, D.P.M. .

Hazards of Giant Hogweed

J. C. Drever, D.C.H., and J. A. A. Hunter,

M.B. ......................109

Adenoid-chest Syndrome?

J. A. Kuzemko, M.D., D.C.H.

R.S.V. Infections and Infant Deaths

G. E. D. Urquhart, M.B., and A. A. M.

Gibson, M.R.C.PATH. .............
Mark Akenside 1721-70

J. Le Gassicke, M.R.C.P.ED. . . . . . . . . 110

Rheumatoid Factor, Vascular Damage, and Hypertension

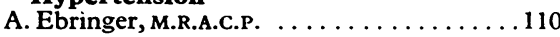

Consultancy in Radiology

G. D. Duncan, D.P.H.; J. A. Ross, F.R.C.P.ED. 110

\section{Regional Consultants}

J. J. Shipman, F.R.C.S., and others . . . . 111

Examination of Immigrant Doctors

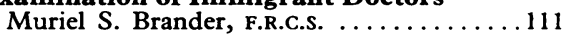

Government and the Review Body

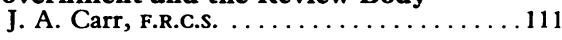

Referendum Results

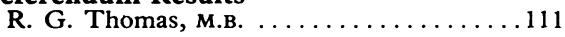

\section{Specialty of Haematology}

SIR,-Your leading article on this subject (27 June, p. 743) contains certain statements, particularly regarding the attitude of the Royal College of Pathologists, upon which I would like to comment. In the first place you give an impression that there is virtual unanimity among haematologists as to the training and examination structure that they consider ideal for their specialty. This is far from being the position, and it is because this College has been hearing strongly conflicting opinions on these matters that its response has been, as you say, "muted." In short, we have thought it wise to weigh the case for change carefully and to consider all the suggested directions of change in some detail before altering a system that has undoubtedly within a few years markedly raised the standards of haematological practice in Great Britain.

This College has, since its founding in 1962, designed its training recommendations and its examinations with the object of ensuring that a successful candidate is competent to take charge of a laboratory concerned with his specialty and to advise on the clinical implications of his work. The appointments recognized in haematology departments have included duties in anaemia clinics and the examinations include the testing of a candidate's knowledge of the clinical aspects of his specialty.

To state, as you do, that "The Royal College of Pathologists ... does not distinguish between the fields of activity of its

\section{Barbiturate-induced Injection Lesions}

SIR,- The contents of proprietary barbiturate capsules including Tuinal ${ }^{\mathrm{R}}$ and Nembutal $^{\mathrm{R}}$ are not entirely water-soluble, and unless particles are removed prior to injection of solutions prepared from such material, as for instance by insertion of a cotton plug in the syringe, then mechanical irritation may ensue.

However, a far more significant factor in members" is so far from the truth that I cannot conceive how you came to print it. From the start the College has insisted that the branches of pathology are separate specialties and that it is unreasonable to expect a specialist in one to deputize in another or to make appointments requiring practice at consultant level in more than one laboratory specialty. The final examinations in the specialties are entirely different and each has been progressively modified over the seven years since they commenced. They have, however, retained the common objective of ensuring satisfactory completion of training in the special branch, including competence to take charge of a laboratory. Once we are confident that the correct formula has been found for modifying any of these schemes we shall not hesitate to make changes.

Your statement that most of the members of the Royal College of Pathologists are histopathologists, which must have been a guess, is also inaccurate: it is possible to determine the proportion with accuracy only for those who have entered the College by examination and of these $43 \%$ are histopathologists, $24 \%$ haematologists, $20 \%$ microbiologists, and $13 \%$ chemical pathologists.--I am, etc.,

\section{T. CRAWFord,}

President,

Royal College of Pathologists.

London S.W.1

relation to the necrotic ulcerating lesions in those who inject barbiturates intravenously as described by Dr. Dorothy I. Vollum (13 June, p. 647) would appear to be the alkalinity of such solutions. The $\mathrm{pH}$ values of aqueous solutions of sodium salts of barbituric acid derivatives are high: a $10 \%$ (w/v) solution of sodium amylobarbitone in water has a $\mathrm{pH}$ value of about 11. The corrosive effect on the gastric mucosa of the soluble barbiturates is familiar to all pathologists in cases of fatal overdosage, and further, though alkaline solutions of thiopentone sodium, for example, may be injected intravenously, it is known that extravasation is liable to cause tissue necrosis. Another contributing factor, especially if injections are made subcutaneously rather than intravenously, may be the hypertonicity or hypotonicity of the solution. A $4.07 \%(\mathrm{w} / \mathrm{v})$ aqueous solution of amylobarbitone sodium is isotonic.

We suggest that the alkalinity of the solution is the prime cause of the necrotic lesions seen in those who self-administer by injection barbiturates intended for oral use. We are, etc.

Francis E. Camps.

ANn E. Robinson.

London Hospital Medical College, London E.1.

\section{Insulin Mixtures and Hypoglycaemia}

SIR,-Recently, a diabetic patient under my care was involved in a serious car accident as a result of a hypoglycaemic episode when he was driving to work.

The patient was usually well controlled on 30 units of protamine zinc insulin and 16 units of soluble insulin, and the only relevant fact which emerged on close questioning was that the patient had been mixing the two insulin preparations in one syringe prior to injection. When asked where he had obtained such instructions, he referred to the drug manufacturers' leaflet. Discussing mixtures of long-acting and soluble insulin, these instructions were as follows: "When a mixture of soluble insulin with these insulins is used, inject air into the bottle of depot insulin but without inverting it or withdrawing the dose. Next, inject air into the bottle of soluble insulin and withdraw the dose in the usual way; then reinsert the needle into the bottle of Protamine Zinc insulin or Isophane insulin and 